\title{
Tobacco consumption and bladder cancer in non-coffee drinkers
}

\author{
G López-Abente, A Escolar
}

Tobacco consumption is the principal known risk factor for urinary bladder cancer. This relation has been analytically characterised on the basis of different aspects of the smoking habit (inhalation pattern, tobacco type, duration). ${ }^{12}$ Other risk factors described for bladder cancer are occupation and coffee consumption, ${ }^{13-5}$ although results for coffee consumption have been contradictory. The important role of cigarette smoking as a confounding factor has been one of the traditional difficulties hindering research into the association between coffee consumption and bladder cancer. In general, studies that have restricted analysis to non-smokers show a weak positive association for coffee consumption, with no effect observed among the smoker stratum. This latter finding is indicative that coffee drinking could have an "attenuator" effect on the risk associated with tobacco use.

In this report, we present the results of a new analysis of the association between cigarette smoking and bladder cancer, in which coffee drinkers were separated from non-coffee drinkers, an aspect that, to our knowledge, has never been published until now.

\section{Methods}

Data came from a multicentre case-control study, the design and results of which have been published elsewhere. ${ }^{25}$ In short, all new cases of bladder cancer diagnosed in the period, January 1985 to March 1986 (incident cases) and all those diagnosed in the period, 1983-1984 (prevalent cases), were included. Cases were selected from 12 general hospitals spread throughout five Spanish provinces (Barcelona, Madrid, Cádiz, Guipúzcoa and Vizcaya) and totalled 497 histologically confirmed cases of carcinoma, polyps and papilloma of the bladder, occurring in men and women under age 80 years at diagnosis and resident in the province where the hospital was located. Two controls (hospital and popula- tion), matched by sex and age ( \pm 5 years), were included for each case, making a total of 583 hospital and 530 population controls.

Interviews were carried out at subjects' homes by trained interviewers who had not been informed as to interviewee case/control status. The questionnaire contained sections dealing with occupational history, tobacco use, passive exposure to tobacco smoke, diet, coffee consumption, use of artificial sweeteners, consumption of analgesics and past history of diabetes, lithiasis and urinary infections. In the section dealing with tobacco use, a complete history was obtained on cigarette, cigar and pipe tobacco consumption, by profiling levels of consumption, tobacco brand, type and characteristics (black, blond, filter and low tar) and duration of all periods in which use occurred. ${ }^{25}$ Non-coffee drinkers were defined as those drinking fewer than two cups a week. A logistic regression analysis was run to estimate the odds ratio (OR) for each variable. All risk estimates shown have been adjusted for age, sex and place of residence.

\section{Results}

Table 1 sets out the distribution of controls with respect to cigarette and coffee consumption. From this distribution, it will be seen that cigarette and coffee consumption are closely linked, proving very similar in both types of controls.

In table 2, estimation of the effect of cigarette smoking is shown separately for the two constituent coffee consumption strata. Among non-coffee drinkers, 30 cases (91\%) were smokers, while among controls the figure was $58 \%$. The effect of cigarette smoking on bladder cancer risk was systematically estimated to be more than double among non-coffee drinkers than among coffee drinkers. The plateau in the effect of smoking over 10 cigarettes/day observed in the initial analysis ${ }^{2}$ was maintained in both strata, as was the dose response effect

\footnotetext{
Hospital Universitario "Puerta del Mar", Servicio de Medicina Preventiva y Salud Pública, Cádiz, Spain A Escolar

Correspondence to: Dr López-Abente, Servicio de Epidemiología del Cáncer, Centro Nacional de Epidemiología, Instituto de Salud Carlos III, Sinesio Delgado, 6, 28029 Madrid, Spain (glabente@isciii.es)

Accepted for publication 6 September 2000
}

Cancer Epidemiology for Epidemiology, Carlos III Institute of Health, Madrid, Spain

Table 1 Distribution of hospital and population controls by smoking habit and coffee consumption

\begin{tabular}{|c|c|c|c|c|c|c|c|}
\hline & \multirow[b]{2}{*}{ Total } & \multirow[b]{2}{*}{ Non-smoker } & \multirow[b]{2}{*}{ Ex-smoker } & \multicolumn{4}{|c|}{ Current smokers (cigarettes/day) } \\
\hline & & & & $1-10$ & $11-20$ & $21-30$ & $31+$ \\
\hline \multicolumn{8}{|l|}{ Coffee drinkers } \\
\hline Hospital controls ${ }^{\star}$ & 393 & $60(15.3) \dagger$ & $85(21.7)$ & $49(12.5)$ & $135(34.4)$ & $46(11.8)$ & $16(4.1)$ \\
\hline Population controls ${ }^{\star}$ & 386 & $63(16.4)$ & $107(27.9)$ & $51(13.3)$ & $111(28.9)$ & $40(10.4)$ & $12(3.1)$ \\
\hline \multicolumn{8}{|l|}{ Ex-coffee drinkers } \\
\hline Hospital controls & 41 & $10(24.4)$ & $17(41.5)$ & $4(9.8)$ & $8(19.5)$ & $1(2.4)$ & $1(2.4)$ \\
\hline Population controls & 43 & $12(27.9)$ & $16(37.2)$ & $4(9.3)$ & $7(16.3)$ & $4(9.3)$ & $0(0.0)$ \\
\hline \multicolumn{8}{|l|}{ Non-coffee drinkers } \\
\hline Hospital controls $\ddagger$ & 57 & $24(44.4)$ & $16(29.6)$ & $8(14.8)$ & $4(7.4)$ & $1(1.9)$ & $1(1.9)$ \\
\hline Population controls & 43 & $17(39.5)$ & $12(27.9)$ & $3(7.0)$ & $7(16.3)$ & $2(4.7)$ & $2(4.7)$ \\
\hline
\end{tabular}

$\star$ Data were missing for two hospital controls and two population controls. $†$ Numbers in parentheses are percentages. $\ddagger$ Data were missing for three hospital controls. 
Table 2 Odds ratios of bladder cancer in male coffee and non-coffee drinkers by cigarette consumption (compared with non-smokers)

\begin{tabular}{|c|c|c|c|c|c|c|c|c|c|}
\hline \multirow[b]{2}{*}{ Variable } & \multicolumn{4}{|c|}{ Coffee drinkers } & \multirow[b]{2}{*}{ Variable } & \multicolumn{4}{|c|}{ Non-coffee drinkers } \\
\hline & Cases & Controls & $O R$ & $95 \% C I$ & & Cases & Controls & $O R$ & $95 \% C I$ \\
\hline Tobacco & & & & & Tobacco & & & & \\
\hline Non-smoker & 24 & 123 & 1 & Reference & Non-smoker & 3 & 41 & 1 & Reference \\
\hline Smoker & 337 & 655 & 2.71 & $1.71,4.31$ & Smoker & 30 & 57 & 7.31 & $2.05,26.11$ \\
\hline Non-smoker & 24 & 123 & 1 & Reference & Non-smoker & 3 & 41 & 1 & Reference \\
\hline Ex-smoker & 69 & 192 & 1.96 & $1.16,3.31$ & Ex-smoker & 6 & 28 & 3.08 & $0.68,13.98$ \\
\hline $\begin{array}{l}\text { Current smoker } \\
\text { Cigarettes/day } \\
\text { among smokers in }\end{array}$ & $\begin{array}{l}268 \\
\text { general }\end{array}$ & 463 & 3.03 & $1.89,4.84$ & $\begin{array}{l}\text { Current smoker } \\
\text { Cigarettes/day } \\
\text { among smokers ir }\end{array}$ & 24 & 29 & 11.72 & $3.06,44.87$ \\
\hline 0 & 24 & 123 & 1 & Reference & 0 & 3 & 41 & 1 & Reference \\
\hline $1-10$ & 33 & 180 & 1.46 & $0.85,2.53$ & $1-10$ & 3 & 27 & 1.33 & $0.24,7.32$ \\
\hline $11-20$ & 206 & 323 & 3.40 & $2.11,5.48$ & $11-20$ & 20 & 19 & 20.09 & $4.85,83.18$ \\
\hline $21-30$ & 58 & 111 & 2.80 & $1.62,4.85$ & $>20$ & 7 & 9 & 10.57 & $2.07,54.09$ \\
\hline$\geqslant 31$ & 22 & 38 & 2.87 & $1.44,5.75$ & & & & & \\
\hline $\begin{array}{l}\text { Cigarettes/day } \\
\text { among current sm }\end{array}$ & hokers & & & & $\begin{array}{l}\text { Cigarettes/day } \\
\text { among current sn }\end{array}$ & hokers & & & \\
\hline 0 & 24 & 123 & 1 & Reference & 0 & 3 & 41 & 1 & Reference \\
\hline $1-10$ & 33 & 100 & 1.75 & $0.96,3.17$ & $1-10$ & 3 & 11 & 2.89 & $0.47,17.69$ \\
\hline $11-20$ & 173 & 246 & 3.81 & $2.33,6.22$ & $11-20$ & 16 & 11 & 34.76 & $6.70,180.26$ \\
\hline $21-30$ & 46 & 86 & 2.97 & $1.67,5.31$ & $>20$ & 5 & 6 & 10.37 & $1.65,65.09$ \\
\hline$\geqslant 31$ & 15 & 28 & 2.84 & $1.31,6.19$ & & & & & \\
\hline Years of smoking & & & & & Years of smoking & & & & \\
\hline 0 & 24 & 123 & 1 & Reference & 0 & 3 & 41 & 1 & Reference \\
\hline $1-19$ & 23 & 60 & 1.85 & $0.96,3.57$ & $1-30$ & 3 & 10 & 3.44 & $0.57,20.60$ \\
\hline $20-39$ & 109 & 235 & 2.23 & $1.34,3.69$ & $>30$ & 27 & 47 & 8.38 & $2.30,30.55$ \\
\hline $40-59$ & 192 & 333 & 3.30 & $2.30,5.37$ & & & & & \\
\hline$\geqslant 60$ & 13 & 27 & 3.09 & $1.36,7.05$ & & & & & \\
\hline Cigarettes/lifetime & & & & & Cigarettes/lifetime & & & & \\
\hline 0 & 24 & 123 & 1 & Reference & 0 & 3 & 41 & 1 & Reference \\
\hline$<150.000$ & 61 & 199 & 1.60 & $0.94,2.71$ & $<150.000$ & 5 & 25 & 2.09 & $0.44,10.02$ \\
\hline 150-299.999 & 149 & 262 & 3.03 & $1.85,4.94$ & 150-299.999 & 17 & 18 & 18.60 & $4.36,79.40$ \\
\hline$\geqslant 300.000$ & 125 & 191 & 3.62 & $2.19,5.98$ & $\geqslant 300.000$ & 8 & 12 & 11.87 & $2.35,59.89$ \\
\hline
\end{tabular}

Non-coffee drinkers exclude ex-coffee drinkers.

for the duration of the habit. The results are similar when the two control groups (hospital and population) are analysed separately.

\section{Discussion}

The results suggest that the relative risk of suffering bladder cancer among cigarette smokers who do not drink coffee may be far higher than that published so far and that exposure to coffee may thus have an "attenuator"' effect on the risk associated with tobacco use. None the less, odds ratios of about 3 were also seen for smoking among coffee drinkers.

Studying non-coffee drinkers by strata is difficult in that the two habits are closely linked, and there is a paucity of cases at the reference level (that is, never smokers). This leads to lack of precision in the estimations. The risk none the less remains very high when a reference level is established composed of non-smokers and ex-smokers.

The role of caffeine in somatic damage induced by carcinogenic agents has been the subject of several studies. In vitro studies indicate that caffeine may have a booster effect on the cytotoxic effect of certain compounds ${ }^{6}$ (for example, DNA intercalating agents). In addition results have been published that point to the role of coffee consumption as effect modifier of other exposures on the risk of cancers with ras mutations. ${ }^{7}$ In contrast, other studies discuss its possible protective effect, by acting as an antimutagenic through formation of complex compounds. ${ }^{8-10}$ All authors are however unanimous when it comes to establishing its influence on DNA repair and damage mechanisms. Furthermore, the toxicity of caffeine seems to be lower among smokers. ${ }^{11}$
Caffeine moreover reduces the number of mutations induced in vitro by a carcinogenic aromatic amine (MeIQx), possibly because of an alteration of the spectrum of enzymes involved in its activation. ${ }^{12}$ Among these enzymes is cytochrome P4501A2 (CYP1A2). Caffeine acts as an inductor of CYP1A2 activity, which may be related to risk of bladder cancer through metabolic activation of aromatic amines and formation of compounds that in turn lead to formation of DNA adducts. ${ }^{13}$ High consumption of coffee (more than four cups of coffee per day) ${ }^{13}$ has been observed to lead to such induction in N-oxidation activity, dependent - among other factors - on CYP1A2.

Recently published results suggest the presence of complex modifying effects phenomenon of the cigarette smoking and coffee consumption in colon cancer ${ }^{14}$ and between alcohol and coffee consumption in liver cancer. ${ }^{15}$ In addition, studies in laboratory animals have shown a protector effect of the caffeine in rats treated with nicotine derived carcinogens ${ }^{16}$ and the inhibition of the cell proliferation and metastatic behaviour of melanoma cancer cells. ${ }^{17}$

The results of our study suggest that the risk of suffering bladder cancer among cigarette smokers may be far higher than that published to date, and that coffee consumption exercises a modulating role, affording a certain protection against the carcinogenic risk associated with smoking. It would be of great interest to evaluate CYP1A2 and acetilisation phenotype activity, along with possible coffee induced modification of tobacco related effects, in future studies on bladder cancer and studies on any other tumour sites that have considered both risk factors. 
We thank Felisa Jaén and Maria Ruiz Tovar for assistance in preparation of tables and suggestions.

Funding: the study was financed by the Fondo de Investigación Sanitaria (FIS) grant 84/745.

Conflicts of interests: none.

1 Howe GR, Burch JD, Miller AB, et al. Tobacco use, occupation, coffee, various nutrients, and bladder cancer. $\mathcal{F}$ Nat tion, coffee, various nutrients,

2 López-Abente G, González CA, Errezola M, et al. Tobacco smoke inhalation pattern, tobacco type, and bladder cancer in Spain. Am $\mathcal{F}$ Epidemiol 1991;134:830-9.

3 Ciccone G, Vineis P. Cofee drinking and bladder cancer. Cancer Lett 1988;41:45-52.

4 IARC. Coffee, tea, mate, methylxanthines and methylglyoxal. Monographs on the evaluation of carcinogenic risks to humans (vol 51). Lyon, France: International Agency for Research on Cancer, 1991

5 Escolar PA, González CA, López-Abente G, et al. Bladder cancer and coffee consumption in smokers and nonsmokers in Spain. Int F Epidemiol 1993;22:38-44.

6 Stoilov LM, Mullenders LH, Natarajan AT. Caffeine potentiates or protects against radiation-induced DNA and chromosomal damage in human lymphocytes depending on temperature and concentration. Mutat Res 1994;311: 169-74.

7 Porta M, Malats N, Guarner L, et al. Association between coffee drinking and K-ras mutations in exocrine pancreatic coffee drinking and K-ras mutations in exocrine pancre

8 Traganos F, Kaminska EB, Darzynkiewicz Z. Caffeine Traganos F, Kaminska EB, Darzynkiewicz Z. Caffeine
reverses the cytotoxic and cell kinetic effects of Novantrone (mitoxantrone). Cell Prolif 1991;24:305-19.
9 Traganos F, Kapuscinski J, Darzynkiewicz Z. Caffeine modulates the effects of DNA-intercalating drugs in vitro: a flow cytometric and spectrophotometric analysis of cine, and the doxorubicin analogue AD198. Cancer Res cine, and the doxo

10 Larsen RW, Jasuja R, Hetzler RK, et al. Spectroscopic and molecular modeling studies of caffeine complexes with DNA intercalators. Biophys f 1996;70:443-52.

11 Carrillo JA, Benítez J. CYP1A2 activity, gender and smoking, as variables influencing the toxicity of caffeine. $\mathrm{Br}$ 7 Clin Pharmacol 1996;41:605-8.

12 Alldrick AJ, Brennan-Craddock WE, Rowland IR. Dietary caffeine reduces the genotoxicity of MeIQx in the caffeine reduces the genotoxicity of MeIQx in the
host-mediated assay in mice. Nutr Cancer 1995;24:143-50.

13 Landi MT, Zocchetti C, Bernucci I, et al. Cytochrome P4501A2: enzyme induction and genetic control in
determining 4-aminobiphenyl-hemoglobin adduct levels. Cancer Epidemiol Biomarkers Prev 1996;5:693-8.

14 Slattery ML, Caan BJ, Anderson KE, et al. Intake of fluids and methylxanthine-containing beverages: association with colon cancer. Int $\mathcal{F}$ Cancer 1999;81:199-204.

15 Tanaka K, Tokunaga S, Kono S, et al. Coffee consumption and decreased serum gamma-glutamyltransferase and aminotransferase activities among male alcohol drinkers. Int f Epidemiol 1998;27:438-43.

16 Lentini A, Kleinman HK, Mattioli P, et al. Inhibition of melanoma pulmonary metastasis by methylxanthines due to decreased invasion and proliferation. Melanoma Res 1998;8:131-7.

17 Chung FL, Wang M, Rivenson A, et al. Inhibition of lung carcinogenesis by black tea in Fischer rats treated with a tobacco-specific carcinogen: caffeine as an important constituent. Cancer Res 1998;58:4096-101. 